\title{
Rise of HR-New Mandates for I-O
}

\author{
William A. Schiemann \\ Metrus Group \\ Dave Ulrich \\ University of Michigan and The RBL Group
}

\begin{abstract}
These are exciting and changing times in the world of business overall and for industrial-organizational (I-O) psychologists in particular. To anticipate where human capital professionals may add the most value to organizations in the future, we asked 73 leading academics, consultants, association leaders, and senior human resources (HR) leaders to articulate what HR professionals need to know and do to be successful in the future. The responses create unique insights on challenges and opportunities for I-O psychologists who want to have impact from their work. We summarize these insights into 7 themes and discuss their implications for an emerging I-O mandate.
\end{abstract}

As advocates for human capital professions such as human resources (HR) and industrial-organizational (I-O) psychology that provide the research and experience base for many decisions made in organizations, we initiated a project to look at what would be required of HR to be successful today and tomorrow in an increasingly demanding and turbulent world. We invited nearly 80 global thought leaders to attend a 1-day conference to discuss this issue and subsequently asked them to write an essay articulating their views. This effort resulted in an anthology (Ulrich, Schiemann, \& Sartain, 2015) that included the thinking of 73 diverse and global human capital thought leaders and has been distributed as an e-book to over 1,500,000 HR professionals and others. This project, sponsored by the HR Certification Institute (HRCI), was presented at the 2016 Annual Society for Industrial and Organizational Psychology Conference in Anaheim. Although the project focused on the role of $\mathrm{HR}$, we believe that there are profound implications for the practice of I-O in organizations as well.

We do not claim to have sampled all of the thought leaders in the field or to have corralled all of the great ideas. Our singular purpose was to ask many

William A. Schiemann, Metrus Group, Somerville, New Jersey; Dave Ulrich, Ross School of Business, University of Michigan, and The RBL Group, Provo, Utah.

Correspondence concerning this article should be addressed to William A. Schiemann, Metrus Group, 953 Route 202 North, Somerville, NJ 08876. E-mail: wschiemann@metrus.com 
key leaders for their thoughts on one key question. What do HR leaders need to know or do to be effective in today's or tomorrow's business world? Although the question sounds simple, answering it is not easy, and answers reflect incredible diversity. It requires granular thinking about human capital across numerous variables: from industry (e.g., public versus private sector) to firm size (e.g., large global firms versus small start-up ventures) to the global reach of an organization's operations. The answer to this question also requires mature thinking about a wide range of $\mathrm{HR}$ functions, from doing administrative or shared service processes more efficiently to providing HR functional expertise, offering integrated HR solutions to deliver strategy, using HR work to serve stakeholders inside and outside the organization, and managing the paradoxes inherent in modern organizations.

Our purpose in this piece is to share not only some of the major insights relating to how HR can be more effective but also how these insights might have a profound impact on the field of I-O psychology. If I-O psychologists were to replace "HR" in the question we asked thought leaders, we believe that I-O psychologists who work in organizations would be likely to have similar answers. Thus, this work impacts I-O psychology in three primary ways:

1. Informs I-O researchers and practitioners about the issues with which organization leaders are wrestling. These issues are likely to have attention at the top of organizations and be supported financially and politically.

2. Stimulates needed theory and research in key areas of I-O psychology to address relevant questions.

3. Helps I-O psychology better package the research that is being done for organizational consumers.

\section{HR or I-O?}

Additionally, although HR and I-O are not isomorphic, they are often highly symbiotic in organizations, with mutual needs and support mechanisms. Both groups are often trying to answer the same questions or resolve the same problems connected to people in organizations. In many organizations, $\mathrm{I}-\mathrm{O}$ psychologists operate within the broad $\mathrm{HR}$ function. Although not everything that we discovered in the Rise of HR project will pertain to I-O, we think that much of it does. I-O theory and research often inform HR practice, and HR challenges may direct future I-O theory and research. ${ }^{1}$

1 Throughout this article we will not always explicitly add a reference to I-O when referring to HR findings, although we think many of the themes are important for future I-O success. We will leave it to the reader to judge which themes are most important to the I-O community and what the implications for current and future practice are. 
We believe-and have seen evidence-that HR and its I-O compatriots can deliver outcomes that matter to many stakeholders:

- Employees have both higher work productivity and higher personal well-being.

- Organizations deliver on business goals and create sustainable cultures or capabilities.

- Customers receive products or services that matter to them.

- Investors have greater confidence in future earnings.

- Communities' (cities, regulators, society) needs are better met.

As these internal and external stakeholders gain value from I-O and $\mathrm{HR}$ concepts, organizations are more successful, and I-O and HR professionals add more value.

\section{Risky or Great Time To Be in Human Capital Seats?}

The increased relevance of HR functions, practices, and professionals to stakeholder outcomes makes this both a great and a risky time to be in HR. The good news is that HR and I-O professionals have more opportunity to influence business success. The Conference Board's 2014 survey of global CEO challenges ranked human capital issues as the number 1 challenge (The Conference Board, 2014). We have also found that the leadership profile of successful CEOs matches the leadership profile of effective chief human resource officers (CHROs; Ulrich \& Filler, 2014) and that HR issues are increasingly a part of firm valuation by thoughtful investors (Bassi, Creelman, \& Lambert, 2014; Ulrich, 2015).

Estimates are that about one third of the issues discussed at the board level are HR related (e.g., succession planning, talent review, executive compensation, governance, strategy execution, ethics, and culture), and those who study boards, such as Mark Nadler, principal and cofounder of Nadler Advisory Services, argue that human capital is increasingly a topic of interest. Although this focus has been slow to emerge, boards are increasingly recognizing the enormous investments they have in human assets and organization capabilities. Boards also are increasingly riveted by the risks that are inherent in their people and organization investments-legal, societal, performance, ethical, competitive, and innovative.

But it is also a risky time to be in HR and I-O because performance expectations are higher and rising. HR professionals are under more scrutiny than ever to respond, as their roles are more important and increasingly visible at the top-in some cases, even under a microscope. With this enhanced visibility and underlying need for insight and foresight in the human capital arena, HR and I-O professionals need to shift from reactive hindsight to proactive foresight, from simple answers to key questions, from complicated 
Table 1. Historical Myths to Modern Realities

\begin{tabular}{|c|c|}
\hline Historical myth & Modern reality \\
\hline $\begin{array}{l}\text { HR professionals go into HR } \\
\text { because they like people. }\end{array}$ & $\begin{array}{l}\text { HR is not just about liking people but about } \\
\text { understanding and solving people-related } \\
\text { problems in organizations. In fact, HR often } \\
\text { requires tough people choices to assure } \\
\text { business results. }\end{array}$ \\
\hline $\begin{array}{l}\text { HR professionals don't believe in or } \\
\text { rely on numbers. }\end{array}$ & $\begin{array}{l}\text { HR has relied on data for years; now more than } \\
\text { ever predictive analytics guide HR decision } \\
\text { making. }\end{array}$ \\
\hline $\begin{array}{l}\text { HR's customers are the employees } \\
\text { in the company. }\end{array}$ & $\begin{array}{l}\text { HR's customers are the leaders, employees, } \\
\text { customers, shareholders, and other } \\
\text { stakeholders of the company; HR work helps } \\
\text { both internal employees and external } \\
\text { customers. }\end{array}$ \\
\hline $\begin{array}{l}\text { HR's measure of success come from } \\
\text { delivering the practices related to } \\
\text { HR (e.g., staffing, training, } \\
\text { compensation). }\end{array}$ & $\begin{array}{l}\text { HR is about delivering business results; the } \\
\text { scorecard of HR is the business's scorecard. }\end{array}$ \\
\hline $\begin{array}{l}\text { HR is responsible for the } \\
\text { organization's talent, leadership, } \\
\text { and capability. }\end{array}$ & $\begin{array}{l}\text { Line managers are the primary owners of talent, } \\
\text { leadership, and culture; HR professionals are } \\
\text { architects who design blueprints and inform } \\
\text { choices. }\end{array}$ \\
\hline
\end{tabular}

Note. $\mathrm{HR}=$ human resources.

processes to simple and integrated solutions, from working alone to working together, and from focusing on activity to focusing on outcomes. If they do these things well, they will have more opportunities to influence policy, decisions, and resource allocation that affect all stakeholders.

Indeed, HR is at a crossroads. We believe that HR can rise to this occasion and meet these higher expectations, but it will require changing some historical myths to modern realities (see Table 1 ).

\section{Rising to the Opportunities for HR-and I-O Psychology}

In a world of high change, it is increasingly difficult to predict the future from the past or present. Instead of doing large cloud or crowd data sourcing, we felt that asking thought leaders who represent different perspectives could offer granular insights into the future. The 73 leaders who took up our challenge have published hundreds of books and thousands of articles; they represent a cross section of global business in multiple industries, and they are in positions to offer thoughtful insights on the future.

We did not have a preconceived framework for how these thought leaders would answer our central question; in fact, we were pleasantly surprised at the diversity of their answers. On the basis of our 1-day session with these 


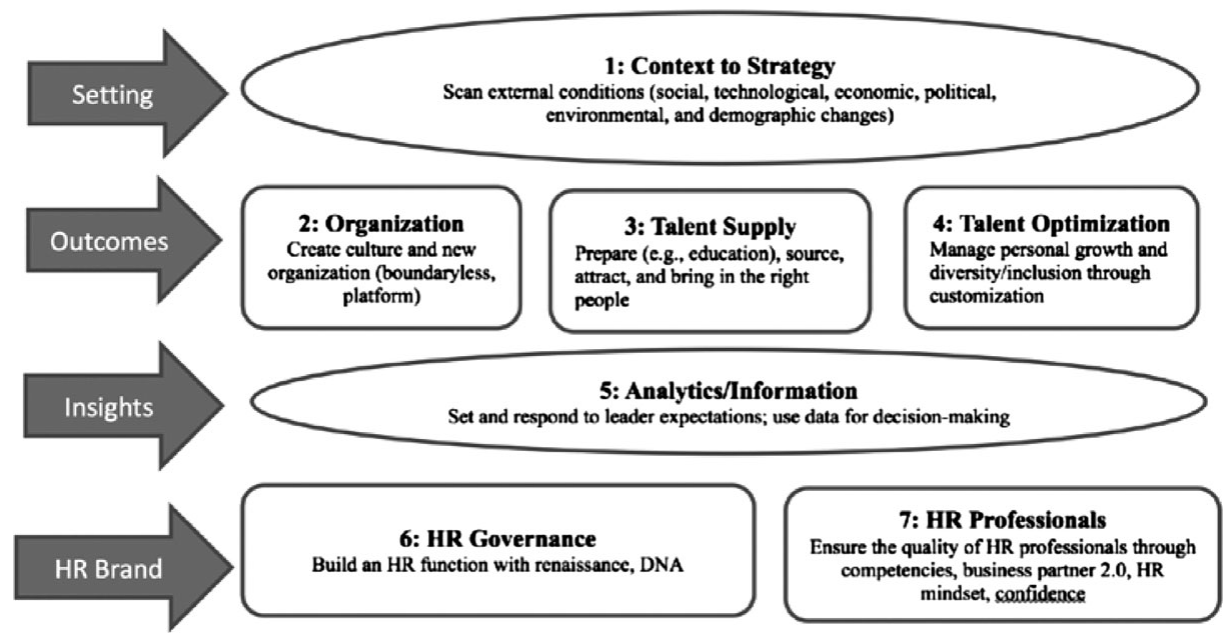

Figure 1. Logic and Flow of Human Resources (HR) Insights

leaders, we distilled their ideas and categorized their essays into seven key themes that will help HR professionals be more effective. Figure 1 shows the flow of these ideas, and Table 2 offers some details behind each of the seven themes.

\section{Seven Key Themes}

In the following sections, we share some of the key ideas from the Rise of HR project and their implications for I-O psychologists' roles in research and organizations.

\section{Context}

No one can deny that our world is changing-fast. Technology has enabled information to flow rapidly around the world and to dramatically change when, where, and how we live and work. We inhabit global villages where events in any one part of the world quickly become news and often have impact in many other places. Because of this, HR and I-O professionals need to be increasingly aware of global business and social trends because they create the context and set the criteria for doing effective HR (and I-O) work. Business and social conditions are changing what and how work is done and thus setting new standards for HR.

When informed HR professionals tell us about how they can be effective, they often have a relatively long list of general trends that shape their organizations and work.

- Social: Personal lifestyles are changing with respect to families, urbanization, ethics, religion, and expectations of well-being. 
Table 2. Overview of Key Questions and Findings

\begin{tabular}{lll}
\hline Section & HR challenge & Major finding \\
\hline \multicolumn{3}{l}{ Setting: What is the context for doing the right HR work? } \\
$\begin{array}{lll}\text { 1. Context to } & \text { How does HR respond to } & \text { View HR from the outside in; link } \\
\text { strategy } & \text { external trends and help } & \text { HR to external outcomes. }\end{array}$ \\
\end{tabular}

Outcomes: What are the outcomes for HR work? When HR comes to the table, what should they talk about?

2. Organization How does HR build the right Create a competitive organization organizational capabilities, workplace, or systems that through organization diagnosis. make the whole greater than the individual parts?

3. Talent supply How does HR ensure a supply of the right talent into the organization by managing the flow of talent?

4. Talent optimization

How does HR ensure that there is a return on investment in increasingly diverse workforces?

Rethink what type of talent will be needed now and in the future and where it will come from.

Ensure growth of employees by eliminating one-size-fits-all policies, applications of $\mathrm{HR}$ programs; building compelling employer brands supported by integrated HR systems and leader behaviors.

Insights: How can information be used to improve HR decision making and impact?

5. Analytics/ information
How does HR provide unique insights through analytics and information?
Use data to educate and make decisions that have impact.

HR brand: What is the HR brand for delivering value?

6. HR governance How does the HR department reinvent itself to have a new DNA and renaissance going forward?

7. HR professionals
How do HR professionals continue to learn and grow for the future?
HR needs to align its structure and build capabilities to deliver more strategic value to their organizations.

Manage yourself and commit to personal improvement.

Note. $\mathrm{HR}=$ human resources.

- Technology: New digital devices and concepts enable access and transparency not only through information but also in relationships, and they can destroy whole industries while bringing new ones to life.

- Economics: Economic cycles shape consumer and government confidence. Freer flow of capital across economic boundaries leads to more granular, or precise, thinking about investments and risk taking, and leads to the development of new industries and the demise of others. 
- Politics: Regulatory shifts change the expectations of government in corporate and personal lives; political unrest often signals a loss of confidence in government institutions.

- Environment: The earth's resources that provide energy for growth are limited and need to be managed responsibly; in addition, social responsibility shapes how people behave.

- Demographics: Changing birth rates, education, and income levels affect employee and consumer behavior. Effective HR professionals are aware of and sensitive to these external conditions, which determine how their organizations position themselves for the future.

These contextual trends provide rich opportunities for I-O professionals to explore theory, research, and practice. They encourage partnerships with professionals in other disciplines that may allow I-O to address issues that cross disciplines. For example, partnerships with economists, demographers, or risk disciplines can provide an opportunity to address issues such as intangible value, millennials, or governance.

\section{Organization}

A second driver of HR effectiveness comes from insights about what organization capabilities will be needed for the successful organization of the future. An organization capability focus shifts the I-O focus from the workforce to the workplace, from people to process, and from individual competencies to organization capabilities. Some of the key capabilities for future $\mathrm{I}-\mathrm{O}$ and $\mathrm{HR}$ attention include

- customer centricity so that there is a line of sight between customer expectations and employee actions;

- organizations built on adaptable platforms rather than hierarchies;

- culture, or glue, which holds organizational systems together in ways that match customer expectations;

- strategy execution through alignment, ability, and architecture;

- collaboration both inside and outside the organization;

- accessing information to make decisions by using analytics for impact; and

- agility or the ability to adapt to change quickly.

Although it may not be clear which one of these capabilities (or others) matters most to any specific organization, it does matter that HR and I-O professionals come to business discussions with the ability to offer insights on the organization, in addition to its talent. By so doing, the war for talent has evolved to a victory through organization. 
Although it is impossible to address all of these themes in one article, a few of themes merit elaboration. Strategy execution has been an important pivot for the last few years in strategic thinking. It is often easier to propose a future state than to realize one. Kenneth J. Carrig, CHRO at a number of companies, and Aki Onozuka-Evans, HR advisor, focus on three organizational requirements that will enhance an organization's ability to execute strategy: alignment (unity or shared direction), ability (human capital or talent pools), and architecture (organizational blueprint or governance) that must all dovetail.

Another key capability is collaboration. Increasingly, complex business requires organizations with the capability of collaboration to accomplish partnerships and alliances, integrate mergers and acquisitions, manage cross-functional teams, and engage employees at all levels. Lynda Gratton, London Business School professor, suggests that because of globalization and increased transparency, HR should be crafting more collaborative organizational cultures. She believes that collaborative organizations not only perform better in the short term but also help an organization's lifespan match the increasing human life expectancy. This would seemingly be an excellent area for I-O psychologists to examine and model. Also, with unprecedented access and availability of information, organizations have to learn how to use, share, and manage information in a more transparent world. Transparency, as an organizational capability, enables organizations to increase commitment from customers and employees, share a common direction across the organization, and meet promises to investors and customers.

No one can dispute the increasing pace of change. When organizations adapt their internal governance to match the external pace of change, they are more likely to succeed. Building agility as an organizational capability becomes central to most organizations today. One of the challenges for I-O psychologists will be a deeper understanding of rapid change. It is becoming harder and harder to design experiments or compare phenomena longitudinally when so many variables are in flux.

Defining the right capabilities for an organization does start with not only what the organization is good at doing but also what customers and consumers outside the organization need the organization to be good at doing. Creating customer-centric capabilities shifts HR from an internal employee to an external marketing focus. Libby Sartain, former CHRO of Southwest Airlines and Yahoo, argues that HR professionals must acquire marketing savvy so that they can connect external customer brand promises to internal employee actions.

Linking external and internal brands is an excellent opportunity area for I-O to partner with professionals in market and brand research to connect those two worlds-ones that have often remained in silos. It raises a number 
of questions for organizations today. Is our employee brand aligned with our customer brand? Are our talent lifecycle processes (e.g., selection, acculturation, training, performance management) aligned with those brands? How do employee characteristics (e.g., engagement, various capabilities, alignment with goals and values) influence an organization's ability to execute on its brand promise? Surely, employees at Walmart, Zappos, Google, Apple, Lenovo, Tata, and McDonald's are engaged in different ways in support of different value propositions.

Creating organizations with an external focus means shifting organizational thinking from hierarchical organizations with clear roles, rules, and responsibilities to organizational platforms. The pillars or the systems sustaining a platform become the capabilities an organization requires to succeed. Regis Mulot, executive vice president at Staples, makes the case for building organizational platforms where there will be increased global collaboration, shared (matrix) decision making, agility and speed of response, and inclusive leadership. He believes that organizations with platforms of these capabilities will win in the global marketplace and that HR will play a key role in making this happen. Also, I-O professionals have an opportunity to test these hypotheses.

\section{Talent Supply}

No discussion of the role of HR now or in the future can be complete without exploring the complex issue of talent, which starts by bringing the right people into the organization (talent supply). I-O psychologists have thousands of studies and insights on talent supply that can inform talent choices.

As Lance J. Richard, vice president (VP) of innovation for Kelly Services, points out, there is not necessarily a shortage of people in the world who are available to work-but there is a shortage of people with the skills we need in the workplace today across the world. This talent mismatch is part of a complex equation, as organizations are looking for workers whose talents and skills match the job and whose work styles and values match their culture. I-O research may help resolve this gap.

Some of the other things I-O and HR professionals can learn about talent supply to be more effective include these:

- Ensuring that the talent hired matches the desired culture. Culture, in this case, is not just values but an organization's identity in the marketplace, so new talent should enhance that desired identity.

- Creating a talent brand that attracts the right employees. One of the best ways to attract and retain talent is helping employees find and have meaning in and purpose from their work. Employee commitment is no 
longer what the company does for you but a mutual responsibility that is a two-way street.

- Seeking talent in diverse and global places. Much of tomorrow's talent will come from nontraditional settings.

- Building unique work arrangements for talent, which may be not fulltime employment but project or contingent work, then learning to manage this contingent workforce so that it works well as a collective team.

- Sourcing high performing talent having the ability to learn and to grow.

- Establishing pipelines into sources of talent earlier in one's career, for example, companies working with schools to prepare future employees earlier in their learning environment.

- Creating more comprehensive strategic workforce plans that capture the variety of talent sources and skills for the future.

In brief, sourcing the right talent becomes a basic for HR or I-O work. I-O psychologists are likely to be more influential in talent sourcing decisions by partnering with functions such as recruiting, advertising, communications, and marketing in the process of finding and hiring the right talent. Further, approaches to selection may need to be reinvented as two phenomena occur: (a) less narrowly defined jobs as roles become broader to meet employee desires and to allow the organization to have more flexibility, which may come from increased contingent or agile workers and (b) more rapidly changing job requirements, therefore making longer criterion validity studies more difficult.

\section{Talent Optimization}

Once people are in the organization (supply), they have to be optimized. People costs are increasingly a higher percentage of total costs and a bigger predictor of success for most organizations. This certainly is true in an expanding service economy in which most of the intellectual capital comes and goes with the people who work in the organization. So the question one needs to ask is this: "Are we optimizing the investment in talent-the collective knowledge, skills, experiences, and behaviors of our people-in the most effective way possible?"

A number of viewpoints relative to talent optimization were discussed by the contributors:

- Engagement

- Fairness

- Innovation 
- Resilience

- Diversity

Although I-O psychologists have been studying satisfaction, commitment, and engagement for many years, the importance of this area has finally bubbled up to the C-suite. David Shadovitz, editor and copublisher of Human Resource Executive magazine, reports that "ensuring workers are engaged and productive consistently occupies the top spot in their recent survey of top HR executives" (Ulrich et al., 2015, pp. 257-262). In fact, in the magazine's 2014 survey, $36 \%$ of $400 \mathrm{HR}$ executives identify engagement as their greatest challenge.

This is a far cry from a decade ago, when many HR leaders were either trying to get their arms around engagement or struggling to sell its importance to the C-suite. Clearly, this is a result of good research that has been done as well as effective marketing at the C-suite level. However, the recent prominence of engagement now begs the question of how best to manage and grow it. Continuing work is clearly needed in this important area. We are now past "building the case" and need to move to solving the engagement gaps. Gallup, Metrus Group, Aon Hewitt, and others have argued that there are many disengaged or partially engaged workers in most organizations, with huge economic consequences to organizations (Aon $\mathrm{He}$ witt, 2011; Schiemann \& Seibert, 2013). Shadovitz offers some practical approaches to address the gap, beginning with better efforts to tailor organizational programs to a segmented workforce. One-size-fits-all approaches are becoming relics in organizations that want to succeed. Another key step is not only conducting regular workforce surveys but also ensuring the findings can be analyzed by relevant segments of the workforce.

William Schiemann, CEO of Metrus Group, Inc., argues that engagement, although important, cannot alone drive organizational performance. He discusses three factors-alignment, capabilities, and engagement-that compose a concept called people equity and why they are a good surrogate for understanding and assessing how well talent is being optimized in the organization. He has shown that the combination of all three factors predict business results, such as quality, customer loyalty, and financial performance in addition to individual outcomes such as turnover.

Sandy Wayne, professor of management at the University of Illinois at Chicago, challenges the traditional idea that equal treatment of all employees is optimal, arguing that equal is not fair and that fair is what attracts, grows, and keeps talent. She notes that HR has long been locked into one-size-fitsall programs and policies, often to the detriment of overall performance.

Linda Hill, professor of business administration at Harvard Business School, discusses the growing urgency for innovation in a world of constant 
change and asks, "How will we develop the leadership talent we need to build and sustain innovative organizations?" Her research at Harvard challenges the widely accepted notion of the leader as a visionary. "Instead of creating a vision and inspiring others to execute that vision," excellent leaders from her study "considered it their role to create a community around shared purpose, values, and norms, and to build organizational capabilities required for innovation." In other words, these leaders believed that everyone has a slice of genius and that "seemingly ordinary people have the potential to make extraordinary contributions to innovation" (Ulrich et al., 2015, pp. 234-240).

William (Bill) Ingham, VP of global HR for Visa, Inc., provides a contrasting perspective to the strategy-driven advocacy of many of the thought leaders, arguing that we need to find our own resilient center before we can truly support others. The notion is akin to airline messaging that asks us to put on our own oxygen mask before helping others. Ingham proposes that "success is based on two characteristics: long-term resilience and the ability to be centered, or 'in the zone,' more frequently" (Ulrich et al., 2015, pp. 241246). This might suggest that talent cannot be optimized if people are not in touch with their own drives.

Last, diversity and social responsibility are major themes espoused and elaborated in works by a number of thought leaders. Women in particular are the focus of several essays highlighting the challenges regarding opportunities for women, ranging from cultural biases to programs to overcome those biases. This is an area not unfamiliar to I-O folks, but it is one that may call for more macrolevel and longitudinal studies within and across organizations to isolate both causes and effects, with realistic recommendations for how to address these social factors that are suboptimizing talent investments in organizations.

All in all, I-O psychologists add value when they help optimize the talent that exists in organizations. Key themes include the importance of engagement (and alignment and capabilities), the leverage of women in the workplace, the value of knowing yourself, the impact of creating a community of shared purpose, and the criticality of looking at each individual uniquely rather than applying one-size-fits-all programs to broad classes of the workforce.

\section{Information and Analytics}

For many HR professionals, measures have been a foreign language. Richard Beatty, coauthor of The Differentiated Workforce, says, "HR analytics and metrics present a significant opportunity to impact the HR profession. In fact, effective use of analytics and metrics may be the biggest contributor to the building of great, sustainable organizations" (Ulrich et al., 2015, p. 285; Beatty, Becker, \& Huselid, 2009). Wayne Brockbank, clinical 


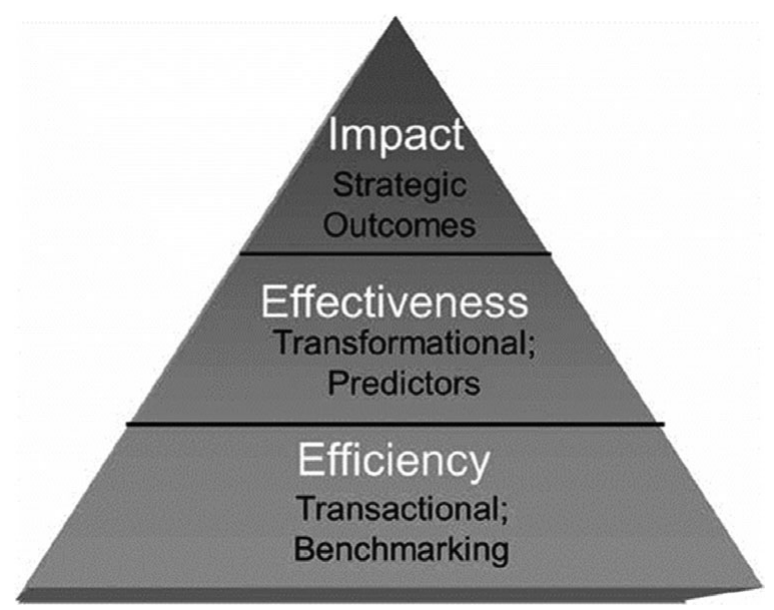

Figure 2. Hierarchy of Measurement

professor of business at the University of Michigan's Ross School of Business, goes even further as he reports on a tracking study that his organization conducts regularly on the role of HR competencies, saying, "The scarce but vital competency ... is the ability of HR professionals to help architect the flow of business information - not just HR information but business information" (Ulrich et al., 2015, p. 297) If we are not mistaken, this is a lob to I-O, with its steep background in scientific method and analytics. This perhaps is the single biggest area for I-O impact-and visibility.

If we think about a hierarchy of measurement as depicted in Figure 2, it is probably not surprising that much of what HR and organizations track is at the transactional level. As pointed out by several of the authors, the use of analytics and measurement should be driven by strategy, not by what's available or easy to collect. What is the theory of the business? What are the talent and organizational implications and requirements? Given the talent and organizational needs, what are the important metrics that HR or the organization should be tracking? Beatty says metrics should be answers to the right questions-before discussing "how" to measure, "we need to explore what might be worth measuring" (Ulrich et al., 2015, pp. 285-294). Sadly today, far too many measures are tactical, easy to capture metrics that don't enable important business decisions, and this has to change.

Mark Huselid, director of the Center for Workforce Analytics at the D’Amore-Kim School of Business at Northeastern University, argues additionally that HR professionals need to focus more on differentiation. Who are the high performers, what are the critical roles, and what are the most strategic requirements of the business? Only then should hypotheses be developed that analytics can help answer. If a business' value proposition is 
to be the most customer-intimate organization in its sector, then the measures that are used in its business, talent, and HR scorecards will be different from those of competitors who are differentiating themselves in other ways. The analytics that are employed should focus on the connection of talent, customer-facing processes, and technology to customer and market goals.

This leads to observations by several authors regarding the dangers of benchmarking when you are comparing your measures with those who may well have different business and talent strategies. If you look again to Figure 2, the easiest level to benchmark is the transactional level: things like training hours per head, turnover rates, time to hire, cost per hire per employee, and so forth. However, this level is the least useful to organizations strategically. These measures may capture efficiency but not effectiveness. A manager leading recruiting may have a time to hire average that is better than some benchmark, but if the organization is losing those hires quickly, is it really effective?

Most of the authors addressing this theme also argue for "outside-in" thinking. For too long, HR generated metrics from the "inside out." Once you are looking through the eyes of the customers of the organization or the stakeholders of HR, the game changes. They, and only they, can provide insights into how they see value being created (or not). In fact, Metrus Institute reports that although overall stakeholder ratings of function (e.g., HR, IT, Finance) value have increased 20 points (out of 100), HR lags other functions in strategic thinking, business acumen, and proactivity (Seibert \& Lingle, 2007). However, their data show that some HR organizations are getting high scores, so this is not an impossible journey. For example, Mark James, named CHRO of the year by Human Resource Executive magazine in 2013, leads a global HR organization at Honeywell that receives high scores from its stakeholders. He attributes this to constant measurement, knowing the business-how widgets are produced-and taking the proactive steps to know what your stakeholders need and whether you are delivering it.

In sum, the thought leaders call for a more strategic approach to measurement and analytics. Start with the market and the strategy, work back to talent requirements and, only then, to HR metrics. Also, develop measures that are answers to important strategic questions. In today's data-rich environments, the risk is creating organizations that are choked by hundreds if not thousands of transactional or tactical metrics and, in doing so, missing the important signals that should be conveyed by the "critical few" scorecard metrics. Metrics should help provide evidence that authenticates or invalidates great hypotheses about what drives value in the organization. Focusing on what information is required to inform business decisions helps measures have more impact. 


\section{HR Governance}

When we think and talk about HR governance, we have historically focused on how HR is organized, where it fits into the broader organizational structure, and how it gets its work done. The changes we have chronicled facing business also will shape how HR organizes to get its work done.

Anthony Nyberg, associate professor at Moore School of Business at the University of South Carolina, and Mike Ulrich, codirector of the Human Resource Competency Study, refer to "Renaissance HR," meaning that HR needs to both broaden and deepen skill sets. John W. Boudreau, professor at the University of Southern California's Marshall School of Business, says that it is time to retool HR and build a profession that is flexible and permeable and that grows quickly by applying the best ideas from other disciplines. I-O faces similar challenges, having been challenged to reach outside of its traditional domain to partner with other expertise areas to address broader and more complex issues that require thinking across disciplines.

Authors such as Mark Blankenship, executive VP of Jack in the Box, Inc., argues for new HR frameworks, starting with a global framework in which HR professionals can contextualize their organizations, their role, and the way they add value. Ron Mester, president and CEO of ERE Media, Inc., challenges long-held HR assumptions and practices, such as talent residing within the organization when, in fact today, a quarter or more of workers reside outside, including many working in the emerging gig economy.

Additionally, many HR and I-O frameworks and applications have been designed for large organizations, when in fact Jorge Jauregui Morales, president of the World Federation of People Management Associations, points out that small and family-owned businesses represent $70 \%$ of employment across the globe.

CHRO Matt Schuyler's HR team at Hilton Worldwide established a values framework, based on the vision defined by Conrad Hilton, which would resonate with team members across the globe. Today, according to Peter Cheese, CEO of CIPD in the United Kingdom, HR needs to take a lead in the real value drivers of business.

While adding new muscle, what might be areas of HR fat that can be shed? Low Peck Kim, CHRO for the Singapore government's Public Service Division, urges HR to shed complexity and focus on what is most relevant to business and customers. Paul Sparrow, professor at Lancaster University Management School, encourages HR to move away from managing the employment relationships to managing risk, governance, and capability across the enterprise. An implication for I-O in this is thinking more broadly about issues such as risk and broader organizational capabilities within which more traditional I-O activities flourish. 
The bottom line is this: HR must have governance models that support value creation. For HR to be effective, it is not just the people in HR but the ways in which HR (and I-O) professionals govern their work to deliver value. HR and I-O win when they can demonstrate value creation for the organization, individual, and society. Peter Cheese, CEO of CIPD in the United Kingdom, reminds us that $70 \%$ or more of the total value in an organization is intangible. Value is driven not just from people and talent but also from organization, capability, and leadership. These drivers are the outcomes of $\mathrm{HR}$ and I-O practices.

\section{HR Professionals}

Being more effective as an HR professional comes from mastering insights from the above sections and building the right knowledge, skills, and experience to anticipate issues, be credible to stakeholders, and deliver results.

A number of efforts have been pursued to define competencies for HR professionals as is displayed in Table 3.

In another study, based on over 36,000 global respondents, the Human Resource Competency Study (HRCS) shared by David Kryscynski, assistant professor at Brigham Young University's Marriott School of Business, and Mike Ulrich identified new HR competencies emerging in this global business context such as the ability to navigate paradox, to become strategic positioners, to be a credible activist, to manage change and culture, and to manage business information.

Clearly a lot of work has been done on HR competencies. We can say with some certainty that HR competency work requires that HR and I-O competencies be tied to personal and business outcomes, that data be collected from observers of $\mathrm{HR}$ and I-O professionals (not just self-report), that data competencies be granular to vary by situation (globalization, level, role, experience), and that competencies become the basis for HR certification and improvement.

Looking forward, HR and its allied professionals must master some baseline competencies to be effective. It is instructive to summarize reflections of successful HR leaders who offer perspectives on specific competencies for future HR success.

- Personal credibility: Dick Antoine, who was the CHRO at Procter \& Gamble and a leader in many HR associations, suggests the importance of credibility with line leaders. Alan May (who was CHRO at Boeing and now Hewlett-Packard) draws on his 30 years of experience in increasing senior HR responsibilities to identify six personal behaviors that should be required for highly successful HR leaders: 
Table 3. Summary of Competencies Studies for HR Professionals

\begin{tabular}{|c|c|c|}
\hline Sponsor & Sample & Major finding \\
\hline $\begin{array}{l}\text { Towers Perrin with } \\
\text { IBM, 1991 } \\
\text { (Brockbank, Ulrich, } \\
\text { \& Beatty, 1999) }\end{array}$ & $\begin{array}{l}\text { Interviewed 3,000 line } \\
\text { managers, consultants, HR } \\
\text { managers }\end{array}$ & $\begin{array}{l}\text { Line wanted HR more computer } \\
\text { literate; consultants predict } \\
\text { change; } \\
\text { HR influences line managers }\end{array}$ \\
\hline $\begin{array}{l}\text { University of Michigan } \\
\text { and The RBL Group } \\
\text { (Ulrich et al., 2009; } \\
\text { Ulrich et al., } \\
\text { 2008;Ulrich, } \\
\text { Brockbank, et al., } \\
\text { 2012;Ulrich, } \\
\text { Younger, et al., 2012) }\end{array}$ & $\begin{array}{l}\text { Six rounds of HR competency } \\
\text { studies from data by HR } \\
\text { and line (sample size): } \\
\text { 1987: 10,291 } \\
\text { 1992: 4,556 } \\
\text { 1997: 3,229 } \\
\text { 2002: 7,082 (with SHRM) } \\
\text { 2007: } 10,063 \text { (with SHRM) } \\
\text { 2012: } 20,103\end{array}$ & $\begin{array}{l}\text { Most recent round (2012) } \\
\text { showed competencies that } \\
\text { predict personal effectiveness } \\
\text { and business results in } 6 \text { areas: } \\
\text { - Strategic positioner } \\
\text { - Credible activist } \\
\text { - Capability builder } \\
\text { - Change champion } \\
\text { - HR innovator and integrator } \\
\text { - Information (technology) } \\
\text { proponent }\end{array}$ \\
\hline $\begin{array}{l}\text { Arthur Yeung and } \\
\text { California Strategic } \\
\text { HR Partnership, } 1996\end{array}$ & $\begin{array}{l}\text { Interviews of senior HR } \\
\text { leaders in } 10 \text { companies }\end{array}$ & $\begin{array}{l}\text { Leadership, HR expertise, } \\
\text { consulting, core competencies }\end{array}$ \\
\hline $\begin{array}{l}\text { Pat Wright and } \\
\text { colleagues, with HR } \\
\text { Policy Association }\end{array}$ & $\begin{array}{l}\text { CHRO focus: } \\
\text { 2009: } 56 \text { CHROs } \\
\text { 2010: } 72 \text { CHROs } \\
\text { 2011: } 172 \text { CHROs } \\
\text { 2012: } 143 \text { CHROs } \\
\text { 2014: } 213 \text { CHROs }\end{array}$ & $\begin{array}{l}\text { CHROs need skills in } \\
\text { - Managing talent } \\
\text { - Cost } \\
\text { - Succession } \\
\text { - Culture } \\
\text { Also defined } 8 \text { roles for HR }\end{array}$ \\
\hline $\begin{array}{l}\text { Center for Effective } \\
\text { Organization }\end{array}$ & $\begin{array}{l}\text { Have done } 6 \text { rounds of study } \\
\text { to show evolution of HR } \\
\text { function over } 15 \text { years } \\
\text { (starting in 1996; Lawler \& } \\
\text { Boudreau, 2012) }\end{array}$ & $\begin{array}{l}\text { Highlight how HR leaders use } \\
\text { time and trends in HR overall } \\
\text { more than specific } \\
\text { competencies }\end{array}$ \\
\hline $\begin{array}{l}\text { (Boudreau \& Ziskin, } \\
\text { 2011; Lawler \& } \\
\text { Boudreau, 2009; } \\
\text { Lawler \& Boudreau, } \\
\text { 2012) }\end{array}$ & & $\begin{array}{l}\text { Hero leadership to collective } \\
\text { leadership } \\
\text { - Intellectual property to agile } \\
\text { cocreativity } \\
\text { - Employment value } \\
\text { proposition to personal value } \\
\text { proposition } \\
\text { - Sameness to segmentation } \\
\text { - Fatigue to sustainability } \\
\text { - Persuasion to education }\end{array}$ \\
\hline $\begin{array}{l}\text { Boston Consulting } \\
\text { Group with World } \\
\text { Federation of People } \\
\text { Management (Strack } \\
\text { et al., 2011; Strack } \\
\text { et al., 2009) }\end{array}$ & $\begin{array}{l}\text { Conduct studies every few } \\
\text { years on HR trends, } \\
\text { particularly in Europe. } \\
\text { 2011: } 2,039 \text { executives }\end{array}$ & $\begin{array}{l}\text { Four critical topics: managing } \\
\text { talent, improving leadership, } \\
\text { transforming HR, strategic } \\
\text { workforce planning }\end{array}$ \\
\hline
\end{tabular}


Table 3. Continued

\begin{tabular}{|c|c|c|}
\hline Sponsor & Sample & Major finding \\
\hline \multirow{3}{*}{$\begin{array}{l}\text { Deloitte (Deloitte, } \\
\text { 2011) }\end{array}$} & \multirow{3}{*}{40 colleagues within Deloitte } & $\begin{array}{l}\text { Five critical HR skills: HR } \\
\text { business partner, HR } \\
\text { processes, recruiting, } \\
\text { restructuring organization, and } \\
\text { leadership development }\end{array}$ \\
\hline & & $\begin{array}{l}\text { Business: commercial awareness, } \\
\text { business acumen }\end{array}$ \\
\hline & & $\begin{array}{l}\text { HR: employee relations, HR } \\
\text { expertise, consulting: trusted } \\
\text { advisor, influence }\end{array}$ \\
\hline \multirow[t]{5}{*}{$\begin{array}{l}\text { SHRM (Lawson, } \\
\text { 1990) }\end{array}$} & $\begin{array}{l}\text { 1989: ASPA builds learning } \\
\text { system with Golle and Holmes } \\
\text { (SHRM, 2009) }\end{array}$ & $\begin{array}{l}\text { This was the foundation of the } \\
\text { learning system for HR } \\
\text { professionals. }\end{array}$ \\
\hline & $\begin{array}{l}\text { 1990: Tom Lawson (1990) } 20 \text { CEO } \\
\text { and } 50 \text { HR interviews }\end{array}$ & $\begin{array}{l}\text { Building management abilities in } \\
\text { leadership, influence, business, } \\
\text { and technology }\end{array}$ \\
\hline & \multirow{2}{*}{$\begin{array}{l}\text { 1998: Steve Schoonover; } 300 \\
\text { interviews in } 21 \text { companies }\end{array}$} & Core competencies \\
\hline & & $\begin{array}{l}\text { Level specific competencies } \\
\text { Role specific competencies }\end{array}$ \\
\hline & $\begin{array}{l}\text { 2002-2007: Partnered with the } \\
\text { Michigan/RBL group }\end{array}$ & $\begin{array}{l}\text { Worked as partner on } 2 \text { rounds } \\
\text { of the Michigan study and } \\
\text { published books and } \\
\text { workbooks on the } \\
\text { competencies }\end{array}$ \\
\hline
\end{tabular}

2013-2015: Did 111 focus groups; Identified 9 competencies across surveyed 640 CHROs and SHRM members 4 levels of HR with proficiency 2015: Job analysis with over 32,000 HR professionals, self-report and validation with 8,000 HR professionals (SHRM, 2012; Alonso et al., 2015)

CIPD profession Generated after an in-depth map (CIPD, 2016) investigation involving detailed interviews with HR directors across all main economic sectors and scores of senior professionals and academics

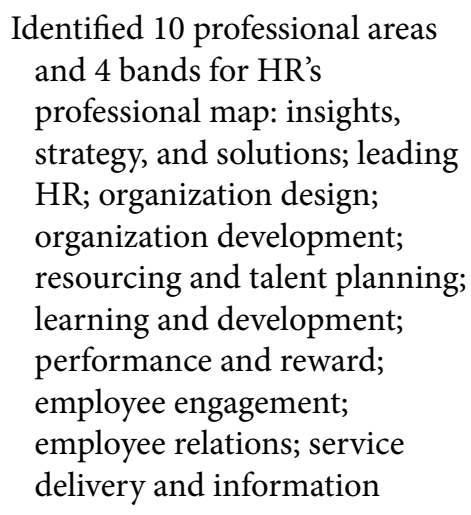

Note. $\mathrm{HR}=$ human resources; SHRM $=$ Society for Human Resource Management; $\mathrm{CHRO}=$ chief human resources officer; ASPA $=$ American Society for Personnel Administration. 
intellectual curiosity, simplicity, empathy, courage, dynamic range, and grit.

- Business knowledge: Lynne Oldham, CHRO for Driscoll's, and Mark James, senior VP of HR, procurement, and communications at Honeywell, with senior HR experience in many companies, drive home the importance of knowing the business. Jill Smart, former CHRO for Accenture and now CEO of National Academy of Human Resources, reinforces the need to know the business through strategic relationships and varied job experiences.

- Evidence driven: Joyce Westerdahl, CHRO at Oracle, following the advocacy of Denise Rousseau, professor at Carnegie Mellon University, advocates that HR professionals follow the path of marketing by having a data driven mindset in all decisions and then leveraging ideas to move faster.

- Business acumen: Fred Foulkes, a leading professor in HR, offers six caveats about CHRO failures as a way to help CHROs prepare for and succeed in the job (overwhelmed, board confidence, management identification, missing signals, business acumen, relationship with all C-suite executives). Donna Morris, $\mathrm{CHRO}$ at Adobe, says the future belongs to HR professionals who embrace the numbers, innovate and adapt, drive employee experience, leverage technology, and think globally and act locally.

Collectively, these HR leaders offer wise counsel to future HR and I-O professionals who want to be effective in their careers.

\section{Now What? Implications for the Profession and for the I-O Professional}

Clearly, in a world filled with unprecedented change, I-O professionals have greater opportunities than ever for influence. But to rise to those opportunities, they need to conduct innovative research and sell proven lessons to global and local leaders in business, government, and education. From these thought leaders, we can identify seven themes that will likely increase effectiveness of I-O and HR professionals: (a) understand the business context to see the world from the outside in, (b) build organization capabilities that deliver business results, (c) increase talent supply, (d) ensure talent optimization, (e) generate information through measures and analytics that add real business value, ( $\mathrm{f}$ ) reinvest the HR department, and (g) master new HR competencies. Knowing and mastering these seven areas will enable I-O and HR professionals to deliver value for different stakeholders-employee engagement, strategy execution, customer loyalty, investor confidence, and community reputation. 
We are not the first, or last, group of I-O and HR observers to call for the professions to rise to the occasion. For decades, advocates and opponents of HR have ruminated about whether $\mathrm{HR}$ and its allies have delivered sufficient value. I-O is often painted with the same brush because of its symbiotic relationship with HR. This progress will come not only from the content on which I-O focuses but also from the processes I-O professionals use to disseminate their ideas, how they collaborate across traditional boundaries to open up new understanding, and how well they translate data to knowledge to decisions.

We advocate that being good researchers, bringing forth defensible data, and sharing knowledge will not be enough to bring I-O to that pivotal role that it could occupy. Instead, I-O will have to become actors in the play, translating good theories and data to practice. Moreover, this may require going beyond traditional boundaries of hypothesis testing and building good theories to getting one's hands dirty in the task of implementing the theories. At times, this will require speculating beyond the known data until better data are available to enable organizations to make good bets or mitigate risk. HR and I-O have to improve both content (what is studied and used) and process (how studies and applications are done) to respond to the opportunities.

\section{Content}

$\mathrm{HR}$ and I-O are increasingly less about HR or I-O and more about business results. Asking "What competencies do professionals need?" is the wrong leading question. It is time to ask "What competencies do professionals need to deliver business results?" As a business imperative, HR outcomes (talent, leadership, and organization) are owned by line executives, with HR and allied professionals being architects, fact finders, coaches, and enablers of how to deliver these outcomes.

The content of value-added HR (and I-O) practices is also woven throughout the above seven themes. There is almost no discussion of specific tools (e.g., how to implement a nine-box performance review or how to manage career bands) but increasing scrutiny of the outcomes of these tools. To deliver value to key stakeholders, HR and I-O professionals offer insight on talent, organizational capabilities, and societal value (e.g., sustainability of knowledge, talent, environment, and communities). Although HR will continue to define problems through ideas, HR must solve problems through rigorous analytics that turn information into insight with impact. I-O psychologists are in an excellent position to shine in this light.

The thought leaders that we sampled in this work argue not only for the bottom line of a profit-and-loss statement but also for broader bottom lines-employee fulfillment, cultural adaptation, and sustainability of talent, environment, community, and family. It might be fair to say that growing 
the bottom lines across many stakeholders is the ultimate win-win: helping organizations accomplish their visions and missions while at the same time enabling their people to achieve their personal visions and life goals. The bottom line for many people is increasingly outside of traditional boundaries. Organizations need talent, whether that comes from traditional employee roles, part timers, contractors, or members of the gig economy. The question is whether individuals and organizations are using that talent for the greatest impact on shareholders, customers, individuals, and communities.

Another key implication is partnering and collaboration. Many of the great world insights in science have come at the boundaries of two or more disciplines. I-O in many ways has morphed with statistics and business to some degree, but there are many other disciplines in which there may be fruitful collaboration-economics, sociology, anthropology, neuroscience, learning, engineering, family and community psychology, quality, and marketing - to name a few. I-O and other fields are at the nascent stage of what will surely be an enormously fruitful collaboration across disciplines.

$\mathrm{I}-\mathrm{O}$ and other scientific disciplines have been recalcitrant to cross the line to fortune tellers, and organizations really don't need fortune tellers. They need evidence-based researchers, practitioners, and leaders who can make educated predictions about what decision to make in various situations. Most of the leaders we deal with regularly know that they don't and won't have perfect information, but they also know that they can't stand still-they must make good bets. I-O psychologists can help with extrapolation and sensible projections of what might be more fruitful avenues, based on principles that have been uncovered by good research. The fields of HR and I-O psychology have rich content that can shape a positive future.

\section{The Process of HR and I-O}

In addition to the content of $\mathrm{HR}$ and I-O, we believe that the process of $\mathrm{HR}$ and I-O will make a big difference in the success of these professions and the ability to adapt each discipline in a volatile, uncertain, complex, and ambiguous (VUCA) world. We have identified four criteria that define the process for doing HR and related professional work. In fact, we embedded these processes into the Rise of HR project.

- Collaboration: In the project, we included input from academics, consultants, CHROs, and industry associations. Many of these authors compete with one another both directly and indirectly, whether in business or in ideas. By openly sharing these ideas with millions of HR and organizational leaders globally, we hope we have introduced both a framework for learning and a spirit of cooperation and collaboration. 
- Innovation: We have tried to report not on what has been done but on what can be done in the future. This means less focus on information that solves puzzles (traditional predictive analytics) than on ideas that shape mysteries (seeking answers to new questions) of what can be done. By aspiring to what can be, HR and I-O will continue to be vibrant and not be mired in tiresome and endless debates about what has been done.

- Application: The gap among theory, research, and practice is mitigated when the focus is application. Application means that theory starts with a problem and works to find a solution that is theoretically robust and replicable. Research is not just about statistical elegance but about getting data that lead to ideas with impact. Practice is not just solving a particular case study or situation but building principles (theory) that endure. This virtuous cycle is evident over and over again in these essays.

- Globalization: The Rise of HR project epitomized what we hope continues to be a trend of thinking and learning globally. The ideas developed in this effort represent thinking from around the world (Asia, Australia, New Zealand, China, India, Europe, the Middle East, and North and South America). Although generic principles of HR and IO may traverse the globe, insights from around the world should be shared.

In brief, we hope that the content of this work and the process of doing the work will increase the likelihood that the HR and I-O professions will make sustainable progress.

\section{References}

Alonso, A., Kurtessis, J. N., Schmidt, A. A., Strobel, K. J., \& Dickson, B. A. (2015). A competencybased approach to advancing HR. People \& Strategy, 38, 38-44.

Aon Hewitt. (2011). Engagement 2.0: State of the American workplace: Employee engagement insights for U.S. business leaders. Washington, DC: Gallup.

Bassi, L., Creelman, D., \& Lambert, A. (2014). The smarter annual report: How companies are integrating financial and human capital reporting. London, UK: Creelman Lambert and McBassi.

Beatty, R. W., Becker, B. E., \& Huselid, M. (2009). The differentiated workforce: Transforming talent into strategic impact. Brighton, MA: Harvard Business Press.

Boudreau, J. W., \& Ziskin, I. (2011). The future of HR and effective organizations. Organization Dynamics, 40, 255-266.

Brockbank, W., Ulrich, D., \& Beatty, R. (1999). HR professional development: Creating the future creators at the University of Michigan Business School. Human Resource Management, 38(2), $111-118$.

CIPD. (2016). CIPD profession map. Retrieved from http://www.cipd.co.uk/cipd-hr-profession/ hr-profession-map/professional-areas/

The Conference Board. (2014). The Conference Board CEO challenge. Retrieved from www. ceochallenge.org 
Deloitte. (2011). Business driven HR: Unlock the value of HR business partners. Retrieved from http:// www2.deloitte.com/ie/en/pages/human-capital/articles/business-driven-hr.html

Lawler, E. E., III, \& Boudreau, J. W. (2009). Achieving excellence in human resources management: An assessment of human resource functions. Stanford, CA: Stanford University Press.

Lawler, E. E., III, \& Boudreau, J. W. (2012). Effective human resource management: A global analysis. Stanford, CA: Stanford University Press.

Lawson, T. (1990). The competency initiative: Standards of excellence for human resource executives. Alexandria, VA: Society for Human Resource Management.

Schiemann, W. A., \& Seibert, J. H. (2013). Optimizing human capital: Moving beyond engagement. People \& Strategy Journal, 36(1), 32-38.

Seibert, J. H., \& Lingle, J. H. (2007). Internal customer service: Has it improved? Quality Progress, March, 35-40.

Society for Human Resource Management. (2009). A history of human resources: SHRM's 60 year history. Alexandria, VA: Author.

Society for Human Resource Management. (2012). The SHRM Competency Model: Elements for HR Success. Retrieved from https://www.shrm.org/LearningAndCareer/competency-model/ Documents/Full\%20Competency\%20Model\%2011\%202_10\%201\%202014.pdf

Strack, R., Caye, J.-M., Teichmann, C., Haen, P., Frick, G., \& Bird, S. (2011). Creating people advantage 2011: Time to act: HR certainties in uncertain times. Boston, MA: Boston Consulting Group.

Strack, R., Caye, J.-M., Zimmerman, P., von der Linden, C., Thurner, R., \& Haen, P. (2009). Creating people advantage 2009: How to tackle the major HR challenges during the crisis and beyond. Boston, MA: Boston Consulting Group.

Ulrich, D. (2015). Leadership capital index. London, UK: Berrett-Koehler.

Ulrich, D., Allen, J., Brockbank, W., Younger, J., \& Nyman, M. (2009). HR transformation: Building human resources from the outside in. New York, NY: McGraw Hill.

Ulrich, D., Brockbank, W., Johnson, D., Sandholtz, K., \& Younger, J. (2008). HR competencies: Mastery at the intersection of people and business. Alexandria, VA: SHRM.

Ulrich, D., Brockbank, W., Younger, J., \& Ulrich, M. (2012). Global HR competencies: Mastering competitive value from the outside in. New York, NY: McGraw-Hill.

Ulrich, D., \& Filler, E. (2014). CEOs and CHROs: Crucial allies and potential successors. Minneapolis, $M N$ : Korn Ferry Institute.

Ulrich, D., Schiemann, W. A., \& Sartain, L. (2015). The rise of HR: Wisdom from 73 thought leaders. Alexandria, VA: HR Certification Institute.

Ulrich, D., Younger, J., Brockbank, W., \& Ulrich, M. (2012). HR from the outside in: Six competencies for the future of human resources. New York, NY: McGraw-Hill. 